\title{
A generalized synthesis load model considering network parameters and all- vanadium redox flow battery
}

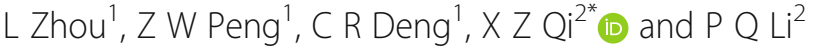

\begin{abstract}
The simulation precision of the classic load model (CLM) is affected by the increasing proportion of installed energy storage capacity in the grid. This paper studies the all-vanadium redox flow battery (VRB) and proposes an equivalent model based on the measurement-based load modeling method, which can simulate the maximum output of the VRB energy storage system and fit the external characteristic of the system precisely in the occurrence of large disturbance and continuous small disturbance. The equivalent model is connected to CLM to form a generalized synthesis load model (GSLM), which considers the parameters of distribution network and reactive power compensation. Compared with CLM, GSLM has better structures and can describe the load characteristics of distribution network with energy storage system more precisely. Simulation results validate the effectiveness and good parameter stability of GSLM, and show that the higher the proportion of energy storage in the grid is the better description ability GSLM has.
\end{abstract}

Keywords: All-vanadium redox flow battery, Classic load model, Network parameter, Parameter identification, Reactive compensation

\section{Introduction}

Renewable clean energy is an important part of smart grid and energy Internet, but it must be combined with energy storage system to meet the requirements of a safe, stabile and efficient large power system. From the perspective of load modeling, the type, composition, and charging and discharging depth of the load model will directly affect the results of the study. Under critical conditions, different load models will lead to complete different simulation and calculation results [1-6]. Under this background, the load model used in the calculation of power system must include energy storage system. The commonly used load model in power system calculation includes induction motor and static load, and the static load is the combination of constant impedance, constant current and constant power loads. It is directly connected to the high voltage load bus and is called the classic load model (CLM) [7, 8]. In actual distribution systems, the

\footnotetext{
*Correspondence: 376563378@qq.com

${ }^{2}$ College of Electrical and Information Engineering, Hunan University,

Changsha 410082, China

Full list of author information is available at the end of the article
}

load is usually connected to the medium and low voltage distribution buses, so CLM may amplify the effect of the motors, leading to errors in the load model. Therefore, developing better-structured load model is of great theoretical value and practical significance.

All-vanadium redox flow battery has attracted wide attention in industry for its noticeable advantages and has been used as energy storage system and operated with clean energy [9-12]. The model of VRB has been studied in many publications. A two-dimensional electrochemical model of VRB is established in [13], which considers the factors of chemical reaction kinetics and can accurately calculate the ion concentration and the dynamic distribution of potential with time and space. The model of VRB including fluid mechanics, electricity and electrochemical multiple physical fields is established in [14]. It uses Bernoulli equation, Nernst equation and some empirical equations to describe the relation between the battery parameters, and the numerical calculation model of the battery system is established from energy perspective. In $[15,16]$, a fourth-order dynamic model of the energy storage battery is established and further improved. The model 
takes into account the nonlinear characteristics of the charging and discharging processes, which have a complex structure with many parameters. The AC impedance model of VRB is established and improved in [17-20], which contains the reaction resistance, ohm impedance, pump damage and additional loss.

Based on the above research, a distribution network simulation model with VRB energy storage system is established in this paper, and the characteristics of the system are obtained at the grid connection bus. From the external characteristics, a simplified equivalent model of VRB energy storage system based on the measurement-based load modeling method is established, which can simulate the maximum output of the VRB energy storage system and fit the external characteristics of the system precisely in the presence of large disturbance and continuous small disturbance. In addition, the model has a simple structure and can be identified easily. The equivalent model is then connected to CLM to form a generalized synthesis load model (GSLM) which considers the parameters of distribution network and reactive power compensation. Compared with CLM, GSLM has better structure and can describe the load characteristics of distribution network with energy storage system more precisely.

This paper is organized as follows. The model of VRB energy storage system is established in Section 2. In Section 3 , an equivalent model of the system is proposed from the principle of external characteristic equivalent fitting. In Section 4, GSLM is established, its parameters are identified, and simulation studies are carried out. Finally, Section 5 draws the conclusion.

\section{VRB model and simulation of grid connected system \\ 2.1 VRB model}

VRB models are divided into electrochemical model and equivalent circuit model according to the principle of modeling. The mathematical equations of the former are complex requiring large amount of calculation, and the necessary micro parameters are difficult to obtain in modeling process. The latter model can directly reflect the external equivalent characteristics of the battery and the changes of various characteristic parameters in the process of charging and discharging are clear. An improved equivalent circuit model based on the assumption of loss [9-11, 18-20] is used in this paper, and the model structure is shown in Fig. 1.

As shown in Fig. 1, the controlled voltage source $U_{s}$ is the open circuit voltage of the battery and $U_{b}$ is the battery terminal voltage. $R_{e a c}$ and $R_{e s}$ represent the internal loss of the battery, which include the diaphragm

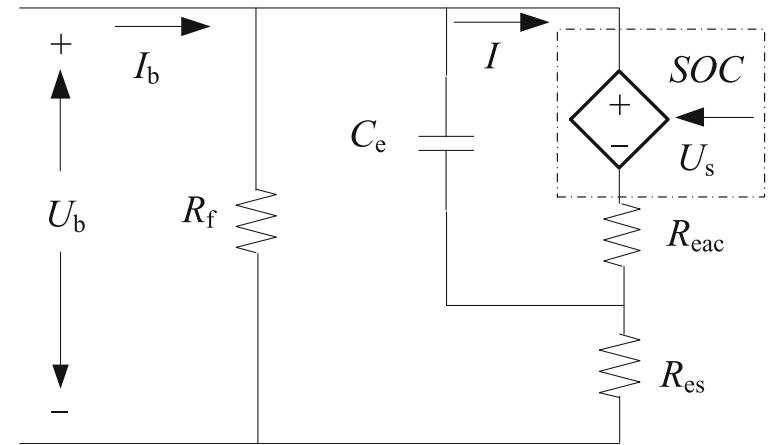

Fig. 1 Equivalent circuit model of VRB

solution impedance and the reaction power equivalent impedance. Many studies have proved that $R_{e a c}$ represents $60 \%$ of the internal loss with $40 \%$ for $R_{e s}[18-20]$. $R_{f}$ represents the pumping loss and additional loss. $C_{e}$ represents the interelectrode capacitance, which simulates the transient state process of VRB, and the equivalent capacitance of a single battery is around 6F.

According to the Nernst equation of electrochemical reaction and ignoring the influence of hydrogen ion concentration, the open circuit voltage of a single battery can be described as:

$$
U_{\text {cell }}=E_{0}-\frac{R T}{F} \ln \frac{C_{3} C_{4}}{C_{2} C_{5}} .
$$

In (1), $U_{\text {cell }}$ is the open circuit voltage of the battery cell, and its unit is V. $C_{i}(i=2,3,4,5)$ represents the concentration of vanadium ion in each valence state, and its unit is $\mathrm{mol} \cdot \mathrm{L}^{-1} . T$ is the absolute temperature with unit of $\mathrm{K}$, and $R$ represents the ideal gas constant and is given as $8.314 \mathrm{~J} \cdot \mathrm{K}^{-1} \cdot \mathrm{mol}^{-1}$. F represents the Faraday constant and equals to $96,500 \mathrm{C} \cdot \mathrm{mol}^{-1}$. When the temperature is $298 \mathrm{~K}$, the positive and negative electrode potential $E_{O}$ between the positive and negative electrodes of VRB is:

$$
E_{0}=E_{0+}-E_{0-}=1.004-(-0.225)=1.259(\mathrm{~V}),
$$

$S O C$ represents the charge state of VRB and is given as:

$$
S O C=\frac{E_{S}}{E_{C}}
$$

where $E_{s}$ and $E_{c}$ are the remaining energy and rated capacity of the battery, respectively. The range of $S O C$ is 0 to 1 . When $S O C=0$, the battery is empty, and when $S O C=1$, the battery is full. $S O C$ can be expressed as a ratio of ionic concentration when the concentration of positive ions equal to the negative.

SOCs for the negative electrolyte and positive electrolyte are given as: 


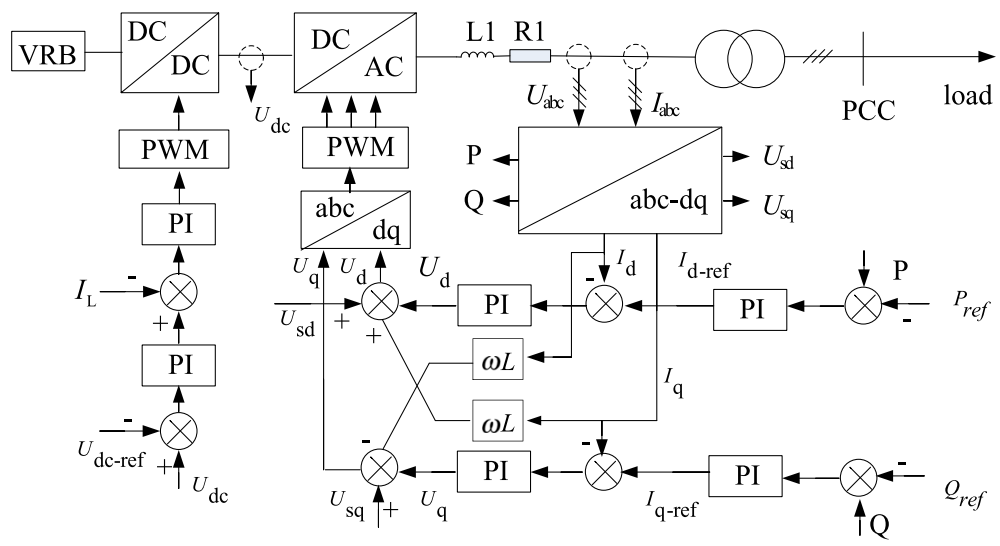

Fig. 2 Control principle of VRB energy storage system

$$
\begin{aligned}
& S_{\text {OC }}=\frac{C_{2}}{C_{3}+C_{2}} \\
& \text { SOC }_{p}=\frac{C_{5}}{C_{5}+C_{4}}
\end{aligned}
$$

When the positive and negative reactions are balanced, the hydrogen concentration is approximately a constant, i.e. $S O C=S O C_{n}=S O C_{p}$. Therefore, the VRB circuit voltage can be described as:

$$
U_{\text {cell }}=1.259-\frac{R T}{F} \ln \left(\frac{1-S O C}{S O C}\right)^{2} .
$$

SOC changes with the battery charging and discharging as:

$$
\begin{aligned}
& S O C_{t+1}=S O C_{t}+\Delta S O C \\
& \Delta S O C=\frac{\Delta E}{E_{C}}=\frac{P_{s} \Delta t}{E_{C}}=\frac{I U_{S} \Delta t}{E_{C}}
\end{aligned}
$$

In the above equations, $\Delta t$ represents the time step, $S O C_{t+1}$ and $S O C_{t}$ are the $S O C$ states of the battery at $\mathrm{t}$ +1 and $\mathrm{t}$ instants, respectively. $\Delta E$ is the total energy change of the battery and $\triangle S O C$ represents the change of the $S O C$ at one time step.

Generally, the voltage of the VRB monomer is not high. In order to match the system voltage, multiple monomers are connected in series to form a stack. For a VRB stack with $N_{\text {cell }}$ numbers of VRB monomers, its open circuit voltage can be described as:

$$
U_{S}=N_{\text {cell }} U_{\text {cell }}
$$

\subsection{VRB energy storage system}

\subsubsection{Construction of VRB energy storage system}

The VRB energy storage system contains a VRB, a converter, and a filter. As VRB outputs DC, a DC/AC converter is required for integrating to the power grid. In this paper, the VRB is connected to the power grid by a bidirectional DC/DC converter, a DC/AC converter and a $\mathrm{LC}$ filter.

The bidirectional DC/DC converter adopts BoostBuck circuit with dual-loop control strategy including a voltage outer loop and current inner loop to achieve bidirectional fast energy flow [21, 22]. The DC/AC converter also adopts dual-loop decoupling control strategy with power outer loop and current inner loop [23]. The active power reference $P_{\text {ref }}$ is the difference between the output active power and the required active power of the grid, and the obtained error is fed to the PI regulator to generate the reference value of the $d$-axis current. The reference value of reactive power $Q_{\text {ref }}$ is set to 0 to ensure unit power factor. When the VRB charges, $P_{\text {ref }}<0$, and the control signal causes the DC/AC inverter to operate in rectifier state, and the $\mathrm{DC} / \mathrm{DC}$ converter in the BUCK mode. When the VRB discharges, $P_{\text {ref }}>0$, the $\mathrm{DC} / \mathrm{AC}$ converter operates in inverter state and the $\mathrm{DC} / \mathrm{DC}$ converter in the BOOST mode.

The block diagram of the overall control diagram of the VRB energy storage system is shown in Fig. 2. $L_{1}$ and $R_{1}$ are the filter inductance and resistance, respectively.

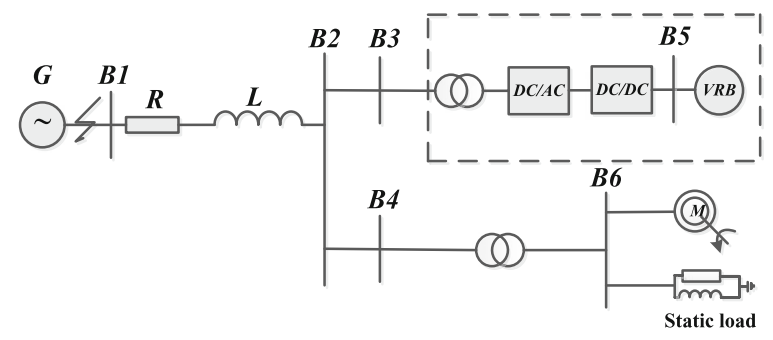

Fig. 3 Grid simulation structure diagram of VRB 


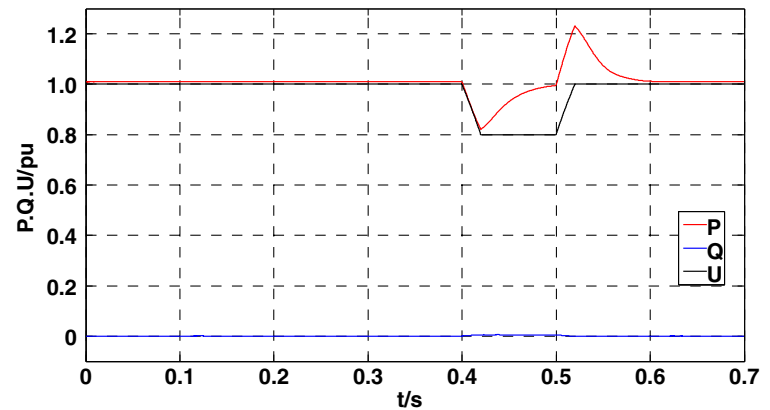

Fig. 4 External characteristics of VRB energy storage system

\subsubsection{Grid simulation}

Based on the previous descriptions, Matlab/Simulink is used to construct the simulation system shown in Fig. 3. The load characteristics of the VRB energy storage system can be obtained by measuring the data at the bus B3.

In Fig. 3, the induction motor simulates the dynamic load, the resistance load in parallel with the inductance load simulate the static load, and the VRB energy storage system is connected to the distribution network through the $\mathrm{DC} / \mathrm{DC}$ and $\mathrm{DC} / \mathrm{AC}$ converters. $L$ and $R$ represent the network parameters.

\section{Equivalent description of VRB energy storage system}

Establishing an equivalent mathematical model describing the external characteristics of VRB energy storage system to meet the demand of power grid simulation is required to study the synthesis load model of distribution network including VRB. An appropriately simplified model is not only a guarantee for accurate power system simulation, but also an essence for reducing simulation difficulty [24]. In this paper, the equivalent model of the VRB energy storage system is established based on the principle of VRB external characteristic fitting.

Table 1 Recognition results of equivalent model parameters

\begin{tabular}{lllll}
\hline Disturbance & $U$ & $T$ & $K_{u}$ & $E_{r}$ \\
\hline Large disturbance & $-10 \%$ & 33.27 & 1.0211 & $2.484 \mathrm{e}-3$ \\
& $-15 \%$ & 33.12 & 1.0445 & $3.796 \mathrm{e}-3$ \\
& $-20 \%$ & 32.39 & 1.0712 & $5.297 \mathrm{e}-3$ \\
& $-25 \%$ & 32.02 & 1.0976 & $6.122 \mathrm{e}-3$ \\
& $-30 \%$ & 31.58 & 1.1246 & $8.233 \mathrm{e}-3$ \\
& $-40 \%$ & 30.63 & 1.1969 & $9.568 \mathrm{e}-3$ \\
Continuous small & $-3 \%,+7 \%,-5 \%$, & 29.20 & 1.0215 & $2.600 \mathrm{e}-3$ \\
disturbance & $+2 \%,-3 \%,+1 \%$ & & & \\
\hline
\end{tabular}

\subsection{Dynamic characteristics of VRB}

In order to study the dynamic characteristics of the VRB energy storage system, the system established in the last section is connected to a power grid. A series of voltage disturbances are applied to test the system. In the process of VRB charging and discharging, three-phase short-circuit faults are applied at bus B1 (see Fig. 3) to cause voltage drops of $10 \%$ to $40 \%$. The load data at B3 (active power, reactive power and bus voltage) are measured and the dynamic characteristics of the VRB energy storage system in transient process are obtained. Taking the $20 \%$ voltage drop as an example, the dynamic characteristic curve of the VRB energy storage system is shown in Fig. 4.

In Fig. 4, in the transient of bus voltage drop, the variation of the reactive power of the VRB energy storage system is very small, and its value is close to 0 . Therefore, to simplify the model, the reactive power is fixed at zero in this paper. The active power $P_{V R B}$ is no longer a constant, and in a dynamic state, the static constant power load cannot describe its transient characteristics accurately, and it must be equivalent to the generalized dynamic load.

\subsection{Equivalent description model of VRB}

Previous analysis shows that it is necessary to establish a dynamic equivalent model to describe the transient characteristics of the VRB energy storage system accurately. According to Fig. 4, the voltage disturbance of the power system can be regarded as superposition of step excitation signals, and the active power output of the VRB energy storage system is close to the step response of the first-order inertial system. Therefore, the step response of the first-order inertial system is used as the equivalent model of the VRB energy storage system after ignoring the reactive power output of the system as:

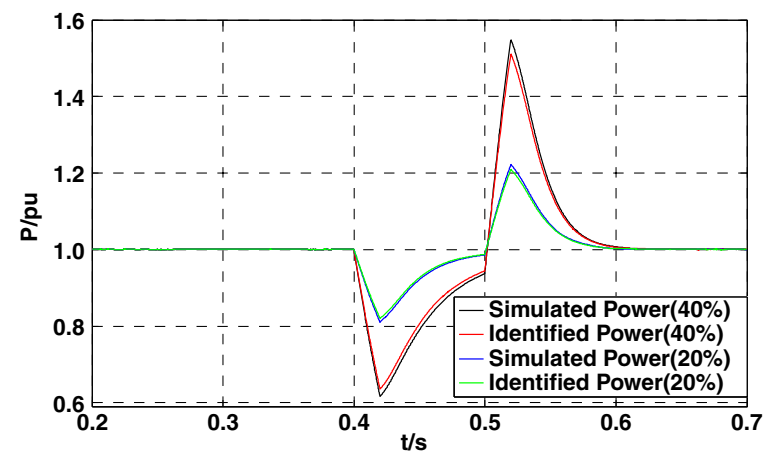

Fig. 5 Fitting curves of the model under large disturbance 


$$
P_{V R B}=2 P_{0}-P_{0}\left[\frac{u}{\tau s+1}+K_{u}\left(u-U_{0}\right)\right]
$$

In (10), $P_{0}$ represents the initial active power output of the VRB energy storage system and is set as the rated power $P_{N V R B}$. The steady-state maximum output active power of the model is $P_{N V R B}$, so this model can simulate the limit output of the VRB energy storage system accurately. $u$ and $U_{0}$ represent the actual and initial values of the system voltage, respectively, and $U_{O}$ equals to the rated voltage $U_{N}$. $\tau$ represents the inertial time constant of the system and $K_{u}$ is the voltage compensation factor.

This model uses the first-order transfer function of voltage to represent the real-time active power output of the VRB energy storage system. The model has limited parameters and the structure is simple, which make the model easy to realize in power simulation software.

\subsection{Verification of equivalent model of VRB energy storage system}

Voltage disturbances can be divided into large disturbance and continuous small disturbance according to the different degrees. When different voltage disturbances occur, the genetic algorithm $[25,26]$ can accurately and

a

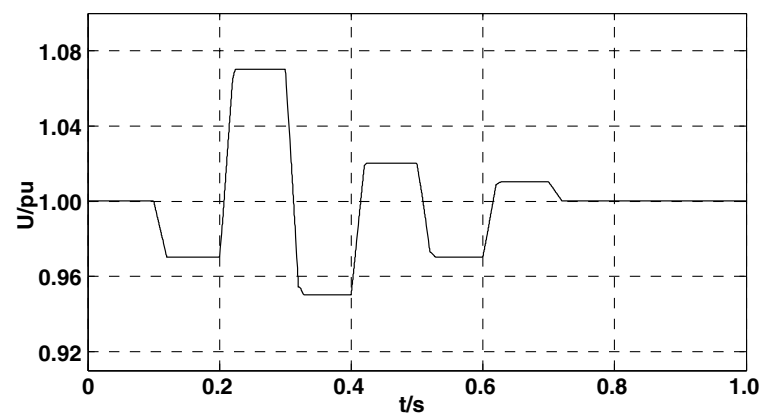

b

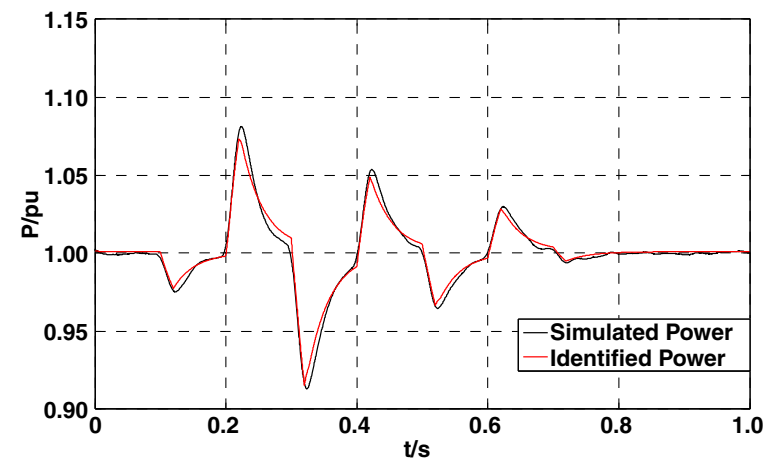

Fig. 6 Voltage disturbance curve and fitting curve of the model under continuous small disturbance quickly identify the parameters of the model, and the output response of the model can then be obtained. The effectiveness of the equivalent VRB model is verified by comparing the output response with the load characteristics of the VRB energy storage system under same disturbances.

\subsubsection{Large disturbance verification}

The system shown in Fig. 3 is simulated and the three-phase short-circuit faults are applied at the bus B1 to cause bus voltage drops of $10 \%-40 \%$. The effective value of the voltage at the bus B3 is the excitation of the model, where the active power curve is the target response curve. The six sets of data as the results of model parameter identification are shown in Table 1.

Experiments on voltage drops of $20 \%$ and $40 \%$ of bus B1 are carried out in this paper, and the fitting curves are shown in Fig. 5.

\subsubsection{Continuous small disturbance verification}

Similarly, a continuous small disturbance is applied at bus B1. The voltage fluctuations and the fitting curves are shown in Fig. 6 (a) and (b), respectively. The identification results are also shown in Table 1.

a

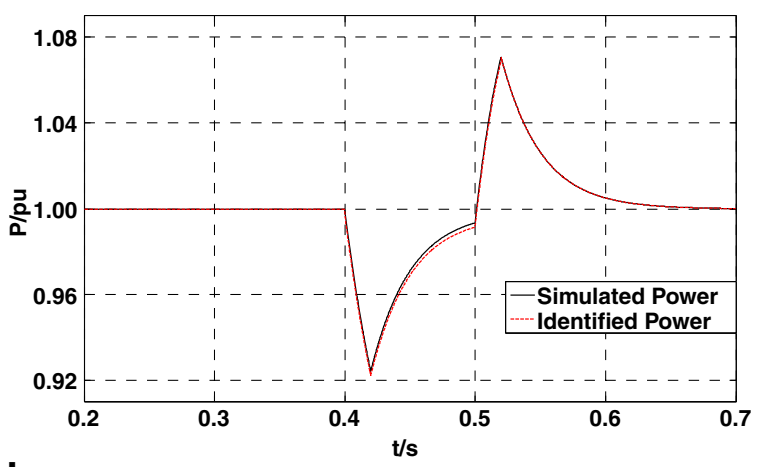

b

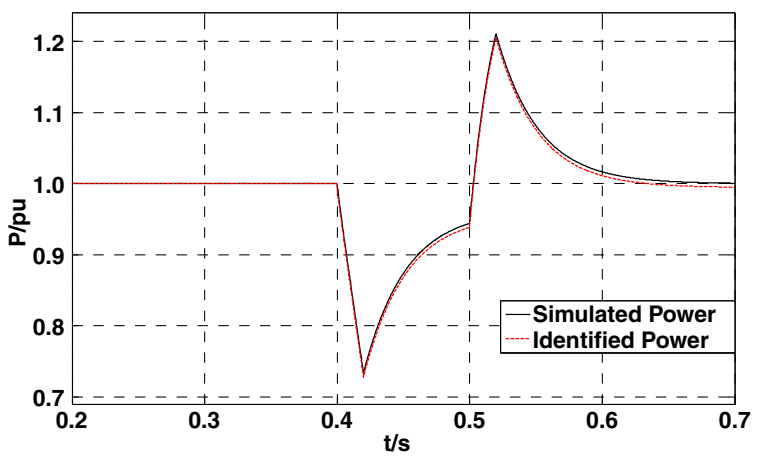

Fig. 7 Interpolation and extrapolation capability verification 
Table 2 Response residuals error of interpolation and extrapolation

\begin{tabular}{lll}
\hline Algorithm & Interpolation 10\% & Extrapolation 30\% \\
\hline residual & $2.501 \mathrm{e}-3$ & $8.593 \mathrm{e}-3$ \\
\hline
\end{tabular}

\subsubsection{Result analysis}

It is seen from Fig. 5 and Fig. 6 that the model response can be well fitted to the load characteristics of the VRB energy storage system in the transient process under both the large and small voltage disturbances. It shows that the equivalent VRB model proposed in this paper is a good approximation to the data samples and has strong self-description ability. The identification parameters and residuals in Table 1 also support this observation. The above analysis shows that the first-order transfer function model proposed in this paper can accurately describe the load characteristics of the VRB energy storage system.

In Table $1, E_{r}$ is calculated according to (11), and its size reflects the degree of the fitting effect. The smaller the $E_{r}$ is, the better the fitting effect has.

$$
E_{r}=\frac{1}{N} \sum_{k=0}^{N} \sqrt{\left(P_{S}(k)-P_{1}(k)\right)^{2}}
$$

In $(11), P_{s}(k)$ is the actual response of the simulation system, $N$ is the measured data length, and $P_{1}(k)$ represents the identification responses.

\subsubsection{Generalization ability test of model}

The model with the parameters identified under voltage drop of $20 \%$ at the bus B1 fits the response curves of the model obtained under bus voltage drop of $10 \%$ (interpolation capability validation) and 30\% (extrapolating ability validation). The generalization ability of the model is verified by comparing the fitting degree of the corresponding model response to the simulation response. The curve of interpolation and extrapolation is shown in Fig. 7, and the fitting residuals are shown in Table 2. The results show that although the voltage excitation amplitudes of the fitting sample and the modeling sample are different, the model has good interpolation and generalization abilities.

It should be pointed out that load model parameter identification is a typical nonlinear mathematical problem, and no optimization algorithm can guarantee the uniqueness of the results. Therefore, it is inevitable that the identified model parameters have certain dispersion.

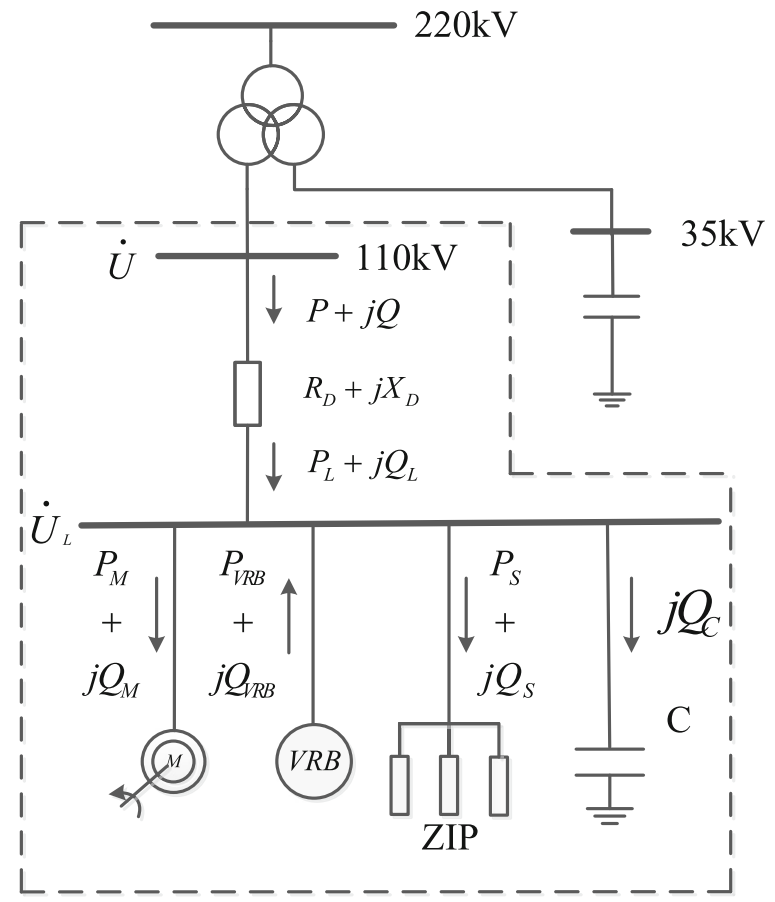

Fig. 8 Structure diagram of GSLM

\section{Structure and parameter identification of GSLM}

CLM does not take into account the influence of distribution grid parameters. Many modeling practices have shown that induction motors have good ability to represent synthesis load, but the ability to describe the reactive power in the transient process after disturbances is poor. Therefore, a dynamic reactive power compensation device is proposed to connect in parallel with the static load [27]. Reference [28] points out that the structure of generalized load model including energy storage system needs to increase the size of the energy storage system on the virtual bus of the synthesis load model. Large numbers of energy storage system can be regarded as the dynamic load with negative power. A generalized synthesis load model with the VRB energy storage system is established in this paper, which takes into account the influence of distribution network parameters and reactive power compensation equipment.

\subsection{The structure of GSLM}

The structure of GSLM is shown in Fig. 8, which takes into account the parameters of the distribution network $R_{D}+j X_{D}$, the compensation capacitor $C$ and the VRB energy storage system. $U$ and $U_{L}$ represent

Table 3 Typical value of non-key parameters

\begin{tabular}{ccccccc}
\hline$R_{S}$ & $X_{r} / \mathrm{pu}$ & $A_{m} / \mathrm{pu}$ & $B_{m} / \mathrm{pu}$ & $C_{m} / \mathrm{pu}$ & $X_{D} / \mathrm{R}_{\mathrm{D}}$ & $\cos \varphi$ \\
\hline 0.03 & 0.12 & 1 & 0 & 0 & 15 & 0.85 \\
\hline
\end{tabular}


Table 4 Six different load levels

\begin{tabular}{llllll}
\hline VRB State & Load Level & $P / \mathrm{pu}$ & $P_{V R B} / \mathrm{pu}$ & $P_{M} / \mathrm{pu}$ & $P_{S} / \mathrm{pu}$ \\
\hline Discharge & 1 & 0.820 & 0.606 & 0.938 & 0.488 \\
& 2 & 0.108 & 0.606 & 0.469 & 0.245 \\
& 3 & -0.131 & 0.606 & 0.313 & 0.162 \\
Charge & 1 & 2.045 & -0.618 & 0.940 & 0.487 \\
& 2 & 1.332 & -0.618 & 0.470 & 0.244 \\
& 3 & 1.094 & -0.618 & 0.313 & 0.163 \\
\hline
\end{tabular}

the actual and virtual load bus voltages, respectively, and the part between the actual and virtual buses is the equivalent impedance of the distribution network.

Assuming that the system frequency is at the rated frequency in normal operation, i.e., $f_{O}=1 p u$, and in per-unit terms, $X=L$.

1) Distribution network parameters

Considering $U=U \angle 0^{\circ}$, as shown in Fig. 8, there are:

$$
\begin{aligned}
& \stackrel{\stackrel{\mathrm{g}}{U}}{L}=\left(U-\frac{P R_{D}+Q f X_{D}}{U}\right)-j \frac{P f X_{D}+Q R_{D}}{U} \\
& \left\{\begin{array}{l}
P_{D}=\frac{P^{2}+Q^{2}}{U^{2}} R_{D} \\
Q_{D}=\frac{P^{2}+Q^{2}}{U^{2}} f X_{D}
\end{array}\right. \\
& \left\{\begin{array}{l}
P_{L}=P-P_{D} \\
Q_{L}=Q-Q_{D}
\end{array}\right.
\end{aligned}
$$

\section{2) Compensation capacitor}

Under the per-unit system:

$$
X_{C}=\frac{1}{\omega C}=\frac{X_{C 0}}{f}, X_{C 0}=\frac{1}{C} \text {. }
$$

Therefore, the capacity of the compensation capacitor is:

$$
Q_{C}=-\frac{U_{L}^{2}}{X_{C}}=-\frac{U_{L}^{2}}{X_{C 0}} f .
$$

where $X_{C O}$ represents the capacitive reactance in normal operation and can be obtained as:

$$
X_{C 0}=-\frac{U_{L 0}^{2}}{Q_{C 0}}
$$

$$
C=\frac{1}{X_{C 0}}=-\frac{Q_{C 0}}{U_{L 0}^{2}}
$$

If $X_{C O}>0$, this part is a real reactive compensation equipment, otherwise, this part is a reactive load and can be incorporated into the static load.

3) ZIP

The static load is equivalent to a constant admittance ( $Y=G-j B$, and if $B>0, Y$ is an inductive load):

$$
\left\{\begin{array}{l}
P_{Z I P}=G U_{L}^{2} \\
Q_{Z I P}=B U_{L}^{2}
\end{array}\right.
$$

\section{4) Motor}

The induction motor has the dynamic characteristics represented by the third-order dynamic differential equations under the synchronous coordinate system. This model is widely used so no further discussion is given here.

\subsection{Unknown parameters of GSLM}

In Fig. $8, P_{M}, Q_{M}, P_{V R B}, Q_{V R B}, P_{S}, Q_{S}$, and $Q_{C}$ represent the active and reactive powers of the induction motor, active and the reactive powers produced by the VRB, active and reactive powers of the static load, reactive power of the compensation capacitor, respectively. The arrows in Fig. 8 represent the reference power directions, and positive power means the direction of the actual power is the same as the reference direction, and vice versa. As can be seen from the previous section, GSLM has a total of 18 parameters, i.e., $R_{D}, X_{D}, X_{M}, R_{S}, X_{S}, R_{r}, X_{r} T_{j}, A_{m}, B_{m}, C_{m}, G, B, X_{C O}$, the ratio of the system reference power to the reference power of the induction motor $K$ [13], $T$ and $K u$ of the equivalent model, and the proportion of the VRB energy storage system $K_{V R B}=P_{V R B} /\left(P_{m}+P_{S}\right)$.

According to [29-31], some of the parameters in the model are difficult to identify and the identification results are discrete. The identification strategy used in this paper only identifies the values of the key parameters, whereas typical values are used for other parameters. Sensitivity analysis shows that among the motor parameters, only $K, X_{S}, R_{r}, X_{m}$, and $T_{j}$ have relatively large sensitivity, and thus, typical values are used for other motor parameters.

For the distribution network parameters, the parameters of GSLM cannot be uniquely identified when $R_{D}$ and $X_{D}$ are unknown. However, when one of their 
values or the relation between them $\left(X_{D} / R_{D}\right)$ is known, the parameters of GSLM is uniquely identifiable [32]. According to the actual statistics, $X_{D} / R_{D}=15$ is used in this paper.

The compensation capacitor $X_{C}$ is calculated as previous described. If $X_{C}$ is not considered separately, the power factor of static load may become abnormal and the calculation results become unreasonable. In order to separate $X_{C}$ from the static load, additional condition is required. To ensure normal power factor for the static load, it is assumed that the power factor $\cos \phi$ is known. As $B / G=\tan \phi$, the relationship between $G$ and $B$ is thus known and $X_{C}$ can be determined once $G$ and $B$ are obtained.

Thus, there are 10 key unknown parameters, i.e., $X_{S}$, $R_{n}, X_{m}, T_{j}, K, G, X_{D}, K_{V R B}, T$, and $K_{u}$. Other parameters can take typical recommended values from China Electric Power Research Institute, as shown in Table 3.

Table 5 Recognition results of generalized synthesis load model parameters

\begin{tabular}{|c|c|c|c|c|c|c|c|c|c|c|c|c|c|c|}
\hline VRB state & Load level & $\Delta U$ & $X_{s}$ & $R_{\mathrm{r}}$ & $X_{\mathrm{m}}$ & $T_{\mathrm{j}}$ & $K$ & $G$ & $X_{D}$ & $K_{V R B}$ & $T$ & $K_{\mathrm{u}}$ & $X_{C}$ & $E_{R}$ \\
\hline \multirow[t]{18}{*}{ Discharge } & \multirow[t]{5}{*}{1} & $10 \%$ & 0.052 & 0.0080 & 5.058 & 2.529 & 1.582 & 0.336 & 0.0065 & 0.359 & 27.35 & 1.180 & -7.61 & $2.3 e-3$ \\
\hline & & $15 \%$ & 0.055 & 0.0079 & 4.916 & 2.525 & 1.555 & 0.307 & 0.0062 & 0.341 & 27.37 & 1.092 & -7.78 & $3.1 \mathrm{e}-3$ \\
\hline & & $20 \%$ & 0.051 & 0.0078 & 5.063 & 2.522 & 1.479 & 0.344 & 0.0064 & 0.361 & 26.87 & 1.033 & -7.50 & $3.5 e-3$ \\
\hline & & $30 \%$ & 0.053 & 0.0080 & 4.990 & 2.497 & 1.485 & 0.335 & 0.0066 & 0.355 & 28.12 & 1.033 & -7.48 & $4.3 e-3$ \\
\hline & & $40 \%$ & 0.054 & 0.0080 & 5.070 & 2.489 & 1.491 & 0.329 & 0.0067 & 0.367 & 28.23 & 1.017 & -7.24 & $5.4 \mathrm{e}-3$ \\
\hline & $\sigma$ & / & 0.002 & 0.0001 & 0.066 & 0.018 & 0.047 & 0.014 & 0.0002 & 0.010 & 0.57 & 0.067 & 0.20 & / \\
\hline & \multirow[t]{5}{*}{2} & $10 \%$ & 0.074 & 0.0079 & 6.576 & 2.482 & 2.655 & 0.205 & 0.0081 & 0.798 & 22.09 & 0.934 & -9.58 & $2.0 e-3$ \\
\hline & & $15 \%$ & 0.079 & 0.0085 & 6.694 & 2.417 & 2.670 & 0.208 & 0.0092 & 0.796 & 22.95 & 0.994 & -9.36 & $2.6 e-3$ \\
\hline & & $20 \%$ & 0.077 & 0.0087 & 6.767 & 2.821 & 2.571 & 0.192 & 0.0086 & 0.790 & 23.68 & 1.084 & -9.90 & $3.4 e-3$ \\
\hline & & $30 \%$ & 0.078 & 0.0078 & 6.659 & 2.539 & 2.597 & 0.206 & 0.0088 & 0.786 & 23.95 & 1.018 & -9.44 & $4.2 e-3$ \\
\hline & & $40 \%$ & 0.076 & 0.0081 & 6.781 & 2.672 & 2.537 & 0.197 & 0.0096 & 0.781 & 24.39 & 0.959 & -9.67 & $5.1 e-3$ \\
\hline & $\sigma$ & / & 0.002 & 0.0004 & 0.084 & 0.161 & 0.056 & 0.007 & 0.0006 & 0.007 & 0.91 & 0.058 & 0.21 & / \\
\hline & \multirow[t]{5}{*}{3} & $10 \%$ & 0.160 & 0.012 & 3.264 & 7.438 & 2.558 & 0.317 & 0.0408 & 1.696 & 26.03 & 0.951 & 11.91 & $3.2 e-3$ \\
\hline & & $15 \%$ & 0.110 & 0.009 & 2.493 & 6.078 & 3.091 & 0.289 & 0.0489 & 1.680 & 24.77 & 1.050 & 14.35 & $3.9 e-3$ \\
\hline & & $20 \%$ & 0.152 & 0.010 & 2.635 & 6.492 & 2.462 & 0.309 & 0.0588 & 1.616 & 23.05 & 1.056 & 12.44 & $4.8 e-3$ \\
\hline & & $30 \%$ & 0.136 & 0.011 & 2.785 & 6.335 & 2.896 & 0.310 & 0.0449 & 1.669 & 24.95 & 1.016 & 13.56 & $5.0 e-3$ \\
\hline & & $40 \%$ & 0.166 & 0.011 & 3.038 & 6.229 & 2.692 & 0.294 & 0.0342 & 1.619 & 25.42 & 1.105 & 13.71 & $5.2 e-3$ \\
\hline & $\sigma$ & / & 0.022 & 0.001 & 0.310 & 0.538 & 0.255 & 0.012 & 0.0092 & 0.036 & 1.12 & 0.057 & 0.99 & / \\
\hline \multirow[t]{18}{*}{ Charge } & \multirow[t]{5}{*}{1} & $10 \%$ & 0.156 & 0.0228 & 4.971 & 0.752 & 0.550 & 0.522 & 0.0214 & -0.516 & 28.29 & 0.970 & 9.20 & $2.6 e-3$ \\
\hline & & $15 \%$ & 0.154 & 0.0245 & 4.631 & 0.782 & 0.561 & 0.521 & 0.0232 & -0.524 & 26.68 & 1.044 & 10.51 & $3.1 e-3$ \\
\hline & & $20 \%$ & 0.167 & 0.0241 & 4.731 & 0.795 & 0.518 & 0.539 & 0.0230 & -0.520 & 23.37 & 1.085 & 9.28 & $3.7 e-3$ \\
\hline & & $30 \%$ & 0.165 & 0.0224 & 4.691 & 0.778 & 0.531 & 0.529 & 0.0231 & -0.524 & 25.91 & 1.056 & 9.59 & $4.1 e-3$ \\
\hline & & $40 \%$ & 0.161 & 0.0232 & 4.669 & 0.783 & 0.578 & 0.525 & 0.0229 & -0.517 & 24.85 & 1.013 & 10.93 & $5.2 e-3$ \\
\hline & $\sigma$ & / & 0.006 & 0.0009 & 0.135 & 0.016 & 0.024 & 0.007 & 0.0007 & 0.004 & 1.86 & 0.044 & 0.78 & / \\
\hline & \multirow[t]{5}{*}{2} & $10 \%$ & 0.056 & 0.0097 & 3.160 & 3.511 & 2.039 & 0.352 & 0.0677 & -1.000 & 22.82 & 1.117 & 7.90 & $3.0 e-3$ \\
\hline & & $15 \%$ & 0.052 & 0.0093 & 3.201 & 3.468 & 2.121 & 0.339 & 0.0668 & -0.988 & 23.06 & 1.016 & 8.92 & $3.5 e-3$ \\
\hline & & $20 \%$ & 0.055 & 0.0089 & 3.095 & 3.495 & 2.026 & 0.369 & 0.0701 & -0.996 & 24.12 & 1.009 & 7.09 & $4.5 e-3$ \\
\hline & & $30 \%$ & 0.055 & 0.0096 & 3.155 & 3.609 & 2.008 & 0.401 & 0.0689 & -0.989 & 22.98 & 1.120 & 6.43 & $5.2 e-3$ \\
\hline & & $40 \%$ & 0.054 & 0.0089 & 3.150 & 3.521 & 2.112 & 0.355 & 0.0694 & -1.002 & 23.25 & 1.007 & 7.67 & $5.3 e-3$ \\
\hline & $\sigma$ & / & 0.002 & 0.0004 & 0.038 & 0.053 & 0.052 & 0.024 & 0.0013 & 0.006 & 0.51 & 0.059 & 0.93 & / \\
\hline & \multirow[t]{5}{*}{3} & $10 \%$ & 0.046 & 0.0077 & 2.206 & 2.949 & 3.767 & 0.258 & 0.0468 & -1.285 & 26.26 & 1.079 & 8.18 & $3.0 e-3$ \\
\hline & & $15 \%$ & 0.044 & 0.0080 & 2.211 & 2.950 & 3.789 & 0.249 & 0.0455 & -1.301 & 25.69 & 1.059 & 8.46 & $4.5 e-3$ \\
\hline & & $20 \%$ & 0.050 & 0.0078 & 2.195 & 2.890 & 3.745 & 0.239 & 0.0466 & -1.269 & 25.98 & 1.068 & 8.40 & $4.8 e-3$ \\
\hline & & $30 \%$ & 0.046 & 0.0081 & 2.099 & 2.996 & 3.698 & 0.255 & 0.0459 & -1.275 & 24.56 & 1.057 & 7.9 & $5.3 e-3$ \\
\hline & & $40 \%$ & 0.048 & 0.0079 & 2.203 & 2.897 & 3.697 & 0.244 & 0.0456 & -1.229 & 23.46 & 1.065 & 8.41 & $5.6 e-3$ \\
\hline & $\sigma$ & / & 0.002 & 0.0002 & 0.047 & 0.044 & 0.041 & 0.008 & 0.0006 & 0.027 & 1.16 & 0.009 & 0.23 & / \\
\hline
\end{tabular}


a

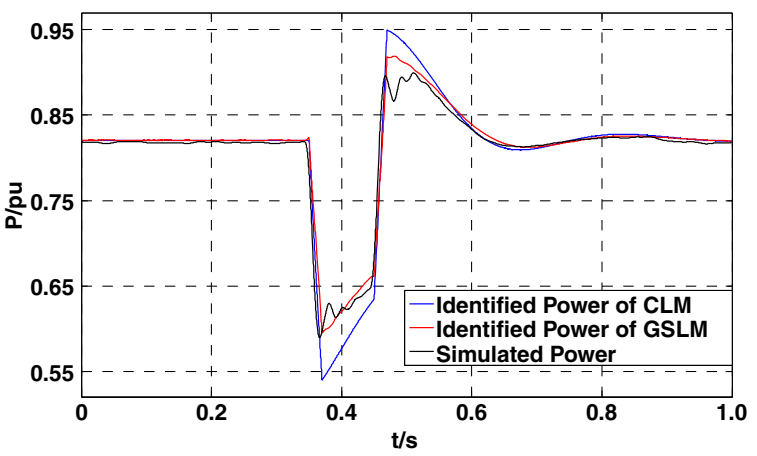

b

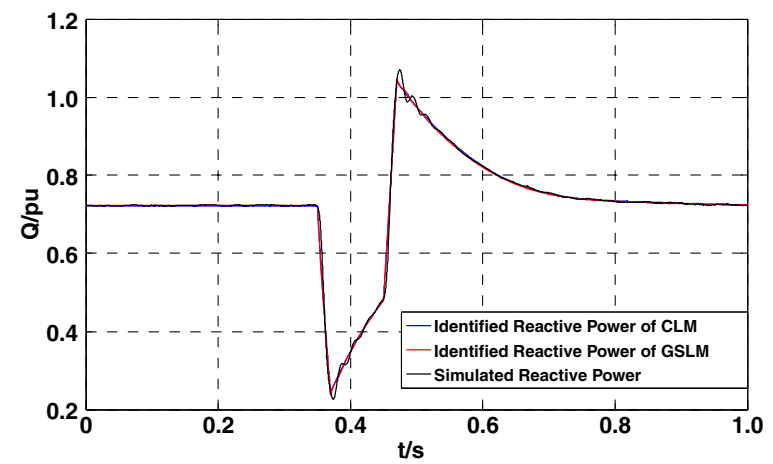

Fig. 9 Fitting curves of the first load level under discharging state

\subsection{Model verification}

To verify the complete GSLM model, the voltage at the bus B1 shown in Fig. 3 is dropped by $10 \%, 15 \%, 20 \%$, $30 \%$ and $40 \%$, respectively, and the model is simulated dynamically under different load levels shown in Table 4. The load data obtained at bus B1 is regarded as the measured sample data, and the parameters are identified by the improved genetic algorithm. The identification results are shown in Table 5, where $\sigma$ represents the standard deviations of the parameters and $E_{R}$ represents the fitting error of the dynamic curve.

In Table $4, P, P_{V R B}, P_{M}$, and $P_{S}$ represent the capacities of the system, VRB energy storage system, dynamic load, and static load, respectively. The fitting effects of the model under the six load levels are described as follows.

\subsubsection{Discharge STATE}

(1) First load level: $0<P_{V R B}<P_{M}$. Under this condition, $K_{V R B}<1$ and the output power from VRB is insufficient to maintain the load power. The powers of the equivalent dynamic load and static load of the distribution network are supplied by the system, i.e., $P>0$, and $Q>0$. From Table 4, the theoretical value of $K_{V R B}$ is a

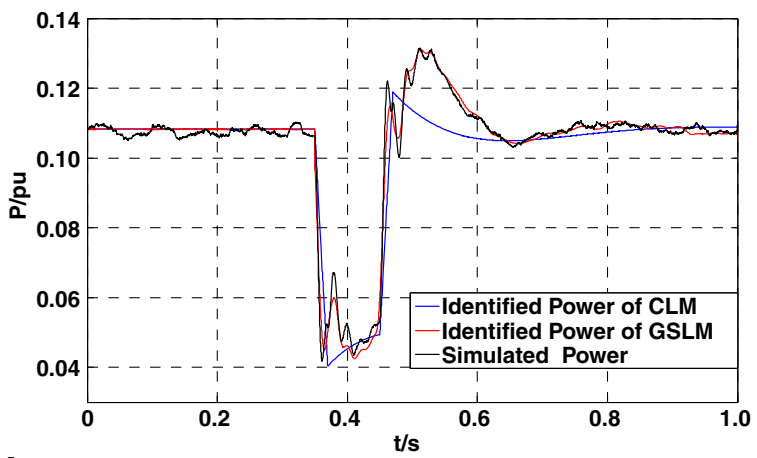

b

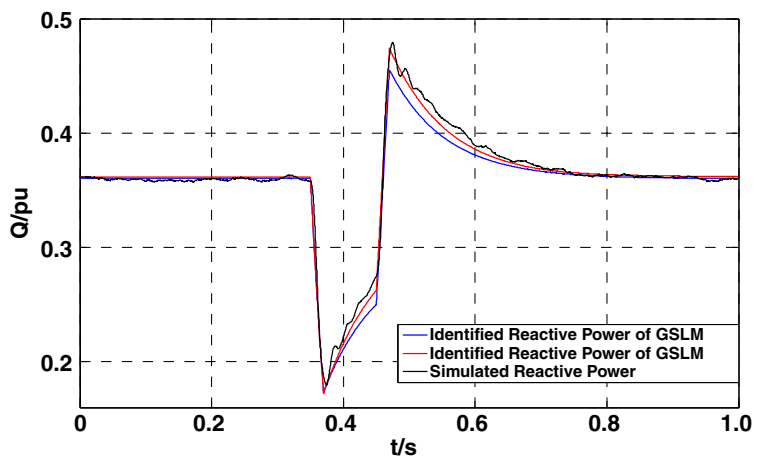

Fig. 10 Fitting curves of the second load level under discharging state

0.425. The fitting effect of the $20 \%$ voltage drop under this load level is shown in Fig. 9.

(2) Second load level: $P_{M}<P_{V E B}<P_{M}+P_{S}$. In this condition, $K_{V R B}<1$, and the output power from VRB fully meets the power absorbed by the induction motor alone, but not the power absorbed by both the induction motor and static load. The theoretical value of $K_{V R B}$ is 0.848 and the fitting effect of the $20 \%$ voltage drop under this load level is shown in Fig. 10.

(3) Third load level: $P_{V R B}>P_{M}+P_{S}$. Under this condition, $K_{V R B}>1$, and the output power from VRB fully meets the power required for the total load, and thus the VRB can input a certain amount of active power to the system, i.e., $P<0$. The theoretical value of $K_{V R B}$ is 1.274 and the fitting effect of the $20 \%$ voltage drop under this load level is shown in Fig. 11.

\subsubsection{Charge STATE}

(1) First load level. The VRB energy storage system acts as a dynamic load to absorb power from the system. The theoretical value of $K_{V R B}$ is -0.433 and the 
a

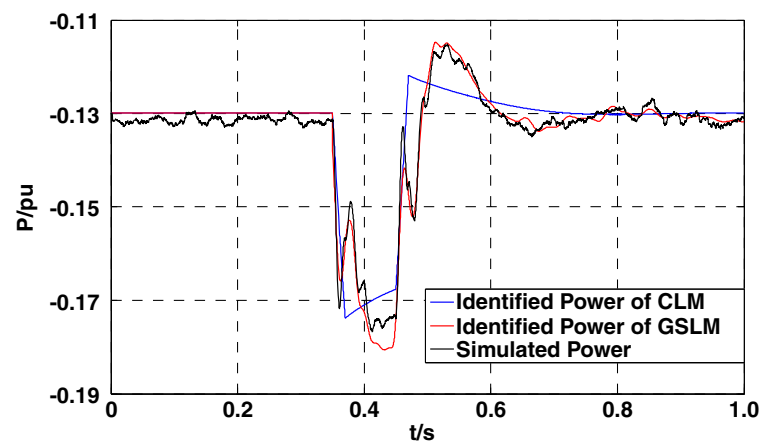

b

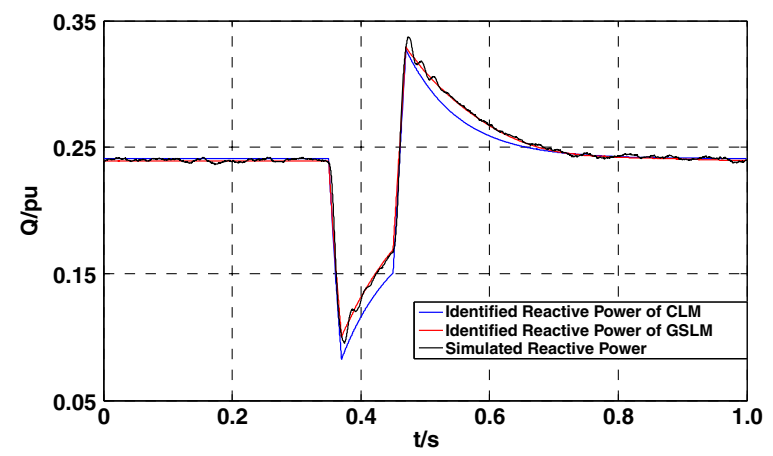

Fig. 11 Fitting curves of the third load level under discharging state

fitting effect of the $20 \%$ voltage drop under this load level is shown in Fig. 12.

(2) Second load level. The proportion of the output power from the VRB energy storage system increases and the theoretical value of $K_{V R B}$ is 0.866 . The fitting effect of the $20 \%$ voltage drop under this load level is shown in Fig. 13.

(3) Third load level. The proportion of the output power from the VRB energy storage system increases further and the theoretical value of $K_{V R B}$ is -1.298 . The fitting effect of the $20 \%$ voltage drop under this load level is shown in Fig. 14.

It can be seen from Figs. 9-14 that the GSLM proposed in this paper can effectively describe the external characteristics of the synthesis distribution network load with the VRB under different load levels and different working conditions, and in charging or discharging states. The errors in Table 5 also indicate that the fitting effect is good.

The corresponding fitting effects of GSLM and CLM to the system simulation are also given in Figs. 9-14. Comparing the curves in the figures and the errors in Table 6, the simulation results of GSLM proposed in this paper show much better performance than that of CLM. With the increase of VRB proportion in the a

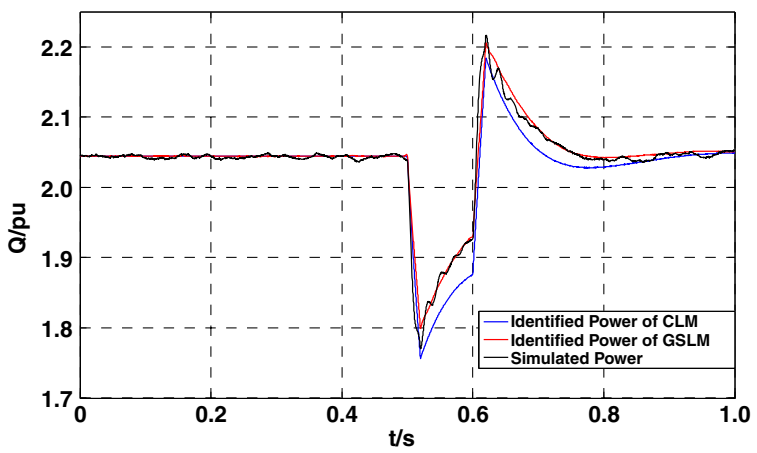

b

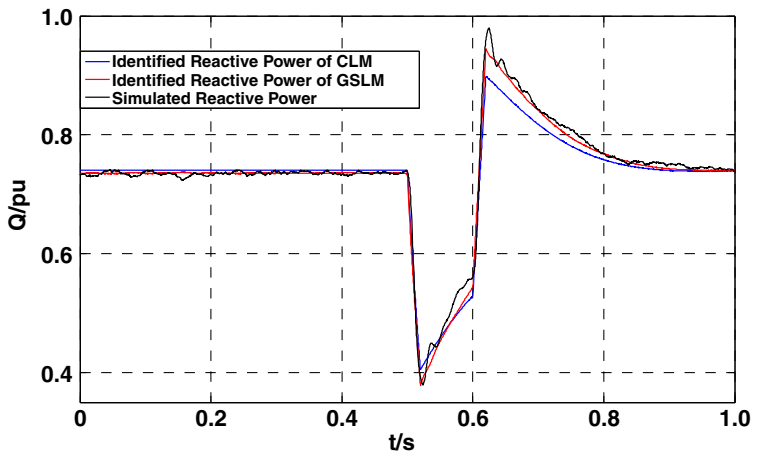

Fig. 12 Fitting curves of the first load level under charging state

distribution network, the errors of CLM increases, whereas for GSLM, the errors are always smaller.

\subsection{Adaptability test of GSLM}

(1) Description ability of the model. It can be seen from Figs. 9-14 that compared with the classic synthesis load model, the proposed model can better simulate the simulation data. The errors in Table 5 also show that the fitting residuals are very small for different load levels and voltage disturbances. Therefore, the model has good approximation effect on data samples and good description ability, which can meet the needs of engineering simulation.

(2) The generalization ability of the model. For six different load levels, the model parameters identified under the $20 \%$ voltage drop fit the response curves of the model obtained under voltage drops of $10 \%$ (interpolation capability verification) and 40\% (extrapolation capability verification). The interpolation and extrapolation capability of the model under different voltage conditions is verified. In this paper, the interpolation and extrapolation curves of the 
a

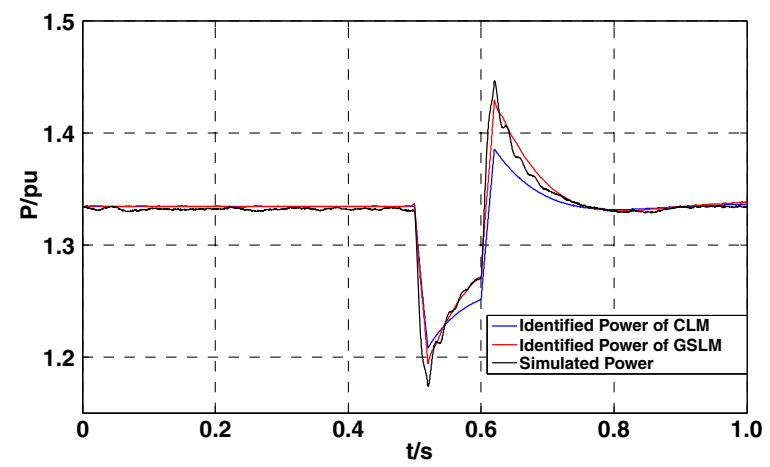

b

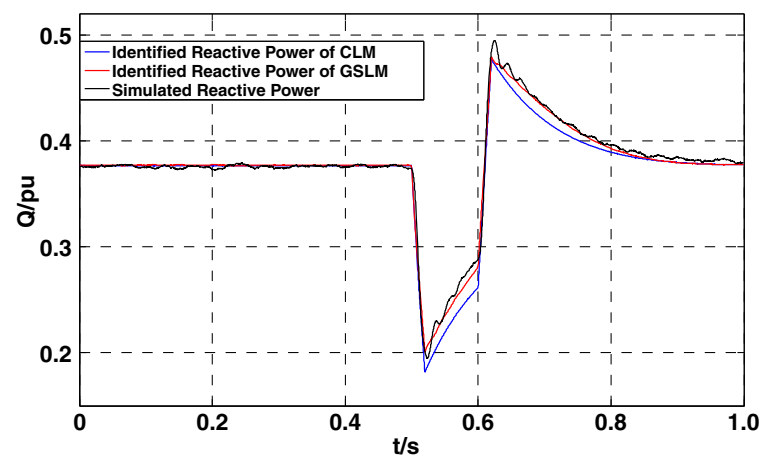

Fig. 13 Fitting curves of the second load level under charging state

discharge state under first load level are given, as shown in Fig. 15, and the fitting residual results are shown in Table 7. Figure 15 shows that although the amplitudes of the voltage disturbances vary significantly, the responses of the identification results to interpolation and extrapolation sample data are well fitted, as indicated by the residuals in Table 7 . The results show that the model has good generalization ability.

(3) Stability analysis of the model parameters. As shown in Table $\mathrm{V}$, except $T$ and $X_{C}$, the standard deviations of the parameters are relatively small indicating good parameters stability. The standard deviations of $T$ and $X_{C}$ are big because their sensitivities are low. Therefore, the overall stability of the model parameters is high.

\section{Conclusions}

In this paper, the equivalent model, which is the step response of the first-order inertial system, is used to describe the external characteristics of the VRB energy storage system. The model can simulate the maximum output of the VRB energy storage system and fit the a

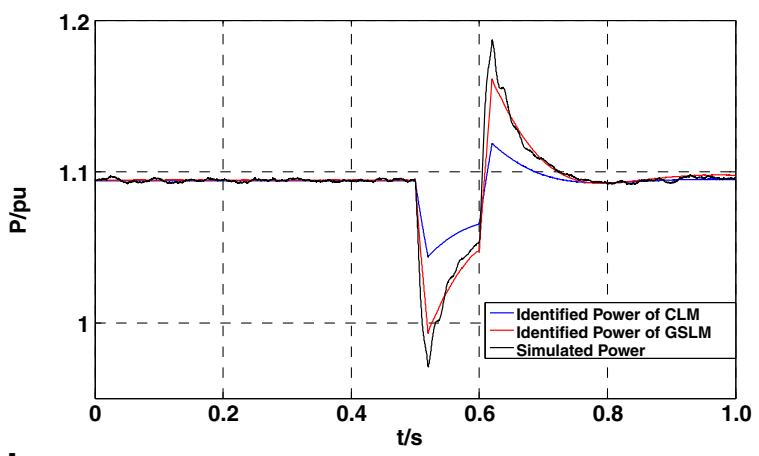

b

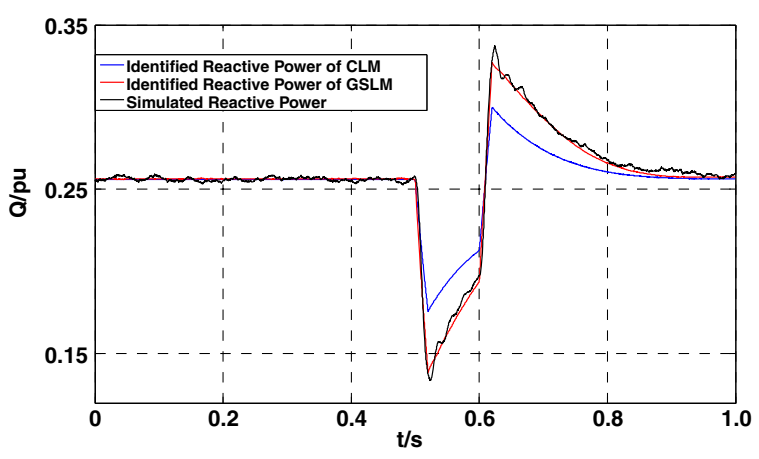

Fig. 14 Fitting curves of the first load level under charging state

external characteristic of the system precisely in the presence of large disturbance and continuous small disturbance. In addition, the model has a simple structure and can be identified easily. On this basis, a generalized synthesis load model (GSLM) with the VRB energy storage system is established, and the distribution network parameters and reactive power compensation are considered. The load characteristics of the distribution network are identified. Simulation results of six typical examples show that GSLM can effectively describe the

Table 6 Error comparison of GSLM and CLM

\begin{tabular}{llll}
\hline VRB state & Load level & Model & $E_{R}$ \\
\hline Discharge & 1 & GSLM & $3.5 \mathrm{e}-3$ \\
& & CLM & $9.2 \mathrm{e}-3$ \\
& 2 & GSLM & $3.4 \mathrm{e}-3$ \\
& 3 & CLM & $2.5 \mathrm{e}-2$ \\
Charge & & GSLM & $4.8 \mathrm{e}-3$ \\
& 1 & CLM & $2.9 \mathrm{e}-2$ \\
& & GSLM & $3.7 \mathrm{e}-3$ \\
& 2 & CLM & $1.2 \mathrm{e}-2$ \\
& & GSLM & $4.5 \mathrm{e}-3$ \\
& & CLM & $2.0 \mathrm{e}-2$ \\
& & GSLM & $4.8 \mathrm{e}-3$ \\
& & CLM & $2.6 \mathrm{e}-2$ \\
\hline
\end{tabular}


a

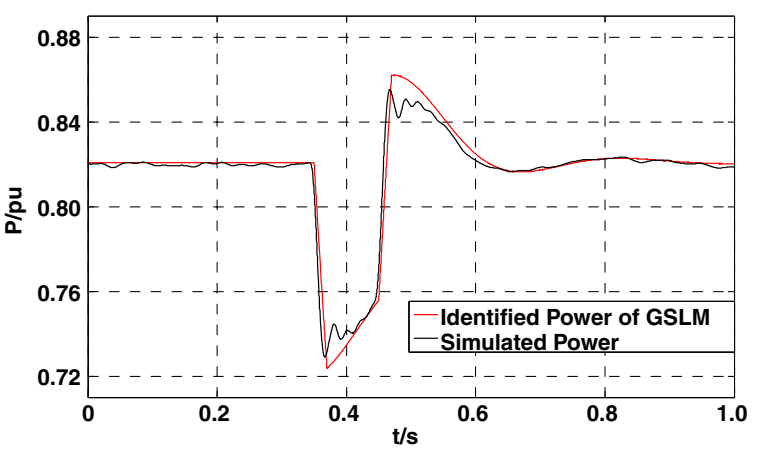

b

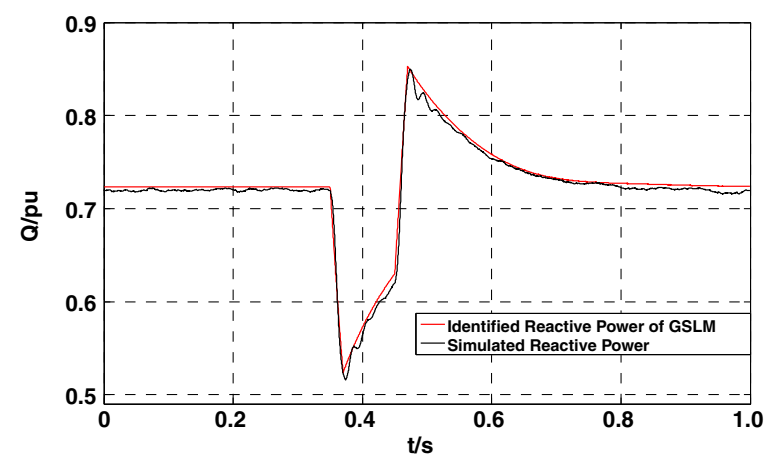

C

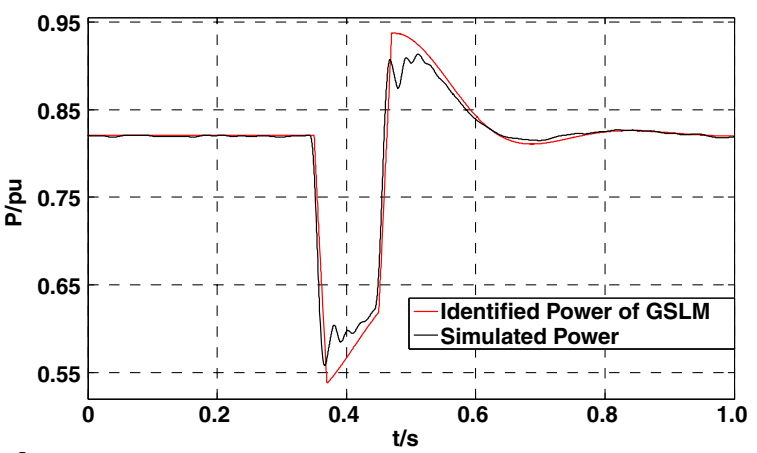

d

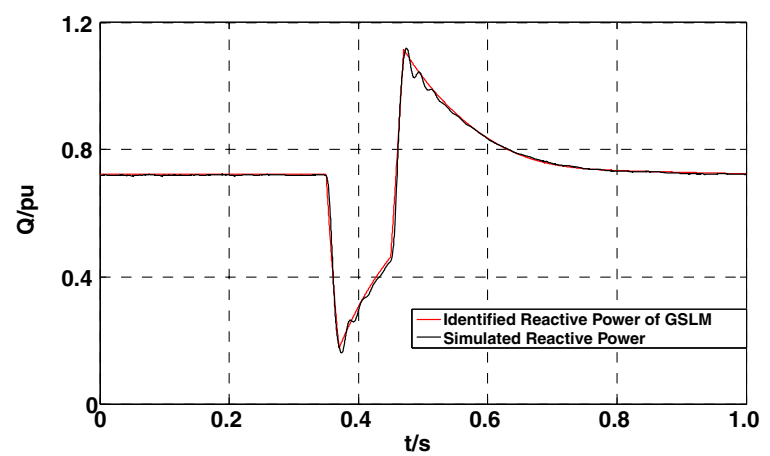

Fig. 15 Interpolation and extrapolation capability verification
Table 7 Response residuals of interpolation and extrapolation

\begin{tabular}{llll}
\hline VRB state & Load level & Interpolation 10\% & $\begin{array}{l}\text { Extrapolation } \\
40 \%\end{array}$ \\
\hline Discharge & 1 & $2.5 \mathrm{e}-3$ & $5.7 \mathrm{e}-3$ \\
& 2 & $2.1 \mathrm{e}-3$ & $5.0 \mathrm{e}-3$ \\
& 3 & $3.3 \mathrm{e}-3$ & $8.6 \mathrm{e}-3$ \\
Charge & 1 & $2.9 \mathrm{e}-3$ & $4.8 \mathrm{e}-3$ \\
& 2 & $3.8 \mathrm{e}-3$ & $5.5 \mathrm{e}-3$ \\
& 3 & $4.6 \mathrm{e}-3$ & $6.3 \mathrm{e}-3$ \\
\hline
\end{tabular}

load characteristics of the distribution network with energy storage system. Compared with CLM, GSLM has better self-description and generalization ability. The model is effective and has good parameter stability, and the higher the proportion of energy storage in the grid is the better description ability the GSLM has.

\section{Abbreviations}

CLM: Classic load model; GSLM: Generalized synthesis load model; VRB: Allvanadium redox flow battery

\section{Funding}

This work was supported in part by the national natural science foundation of China(51677059) and Guangdong Power Grid Company Limited Project. (GDKJXM00000025).

\section{Availability of data and materials}

Data sharing not applicable to this article as no datasets were generated or analysed during the current study.

\section{Authors' contributions}

All authors read and approved the final manuscript.

\section{Competing interests}

The authors declare that they have no competing interests.

\section{Author details}

'Guangdong Power Grid Corporation Information Center, Guangzhou, China. ${ }^{2}$ College of Electrical and Information Engineering, Hunan University,

Changsha 410082, China.

Received: 11 May 2018 Accepted: 18 September 2018

Published online: 15 October 2018

\section{References}

1. Navarro, I. R., Samuelsson, O., \& Lindahl, S. (2003). Influence of normalization in dynamic reactive load models. IEEE Transactions on Power Apparatus and Systems, 18(2), 972-973.

2. Ju, P., Handschin, E., \& Karlsson, D. (1996). Nonlinear dynamic load modelling: Model and parameter estimation. IEEE Transactions on Power Apparatus and Systems, 11(4), 1689-1697.

3. Hill, D. J. (1993). Nonlinear dynamic load models with recovery for voltage stability studies. IEEE Transactions on Power Apparatus and Systems, 8(1), 166-176.

4. Karlsson, D., \& Hill, D. J. (1994). Modelling and identification of nonlinear dynamic loads in power systems. IEEE Transactions on Power Apparatus and Systems, 9(1), 157-166.

5. Kao, W. S. (2001). The effect of load models on unstable low-frequency oscillation damping in Taipower system experience w/wo power system stabilizers. IEEE Transactions on Power Apparatus and Systems, 16(3), 463-472.

6. Pereira, L., Kosterev, D., Mackin, P., Davies, D., Undrill, J., \& Zhu, W. C. (2002). An interim dynamic induction motor model for stability studies in the WSCC. IEEE Transactions on Power Apparatus and Systems, 17(4), 1108-1115. 
7. Ma, J., Renmu, H., \& Hill, D. J. (2006). Load modeling by finding support vectors of load data from field measurements. IEEE Transactions on Power Apparatus and Systems, 21(2), 726-735.

8. Renmu, H., Ma, J., \& Hill, D. J. (2006). Composite load modeling via measurement approach. IEEE Transactions on Power Apparatus and Systems, 21(2), 663-672.

9. Badrinarayanan, R., Yu, Z., \& Tseng, K. J. (2015). Performance study of a vanadium redox flow battery (VRB) for use in green data centers (pp. 1-5). Osaka: IEEE International Telecommunication Energy Conference (INTELEC).

10. Qiu, X., Crow, M. L., \& Elmore, A. C. (2015). A balance-of-plant vanadium redox battery system model. IEEE Transaction on Sustainable Energy, 6(2), 557-564.

11. Qiu, X., Nguyen, T. A., Guggenberger, J. D., Crow, M. L., \& Elmore, A. C (2014). A field validated model of a vanadium redox flow battery for microgrids. IEEE Transactions on Smart Grid, 5(4), 1592-1601.

12. Guggenberger, J. D., Elmore, A. C., Tichenor, J. L., \& Crow, M. L. (2012). Performance prediction of a vanadium redox battery for use in portable, scalable microgrids. IEEE Transactions on Smart Grid, 3(4), 2109-2116.

13. Shah, A. A., Watt-Smith, M. J., \& Walsh, F. C. (2008). A dynamic performance model for redox-flow batteries involving soluble species. Electrochimica Acta, 53(27), 8087-8100.

14. Blanc, C., \& Rufer, A. (2008). Multiphysics and energetic modeling of a vanadium redox flow battery. In Proc. IEEE 2008 International Conference Sustainable pp. 696-701. Singapore: Energy Technol.

15. Kroeze, R. C., \& Krein, P. T. (2008). Electrical battery model for use in dynamic electric vehicle simulations. IEEE Transactions on Power Apparatus and Systems, 23(4), 1336-1342.

16. Zban, C. J., Wu, X. G., Kromlidis, S., et al. (2003). Two electrical models of the lead-acid battery used in dynamic voltage restorer. IEEE Proceedings Gener Transm Distrib, 150, 2175-2182.

17. Chahwan, J., Abbey, C., \& Joos, G. (2007). VRB modelling for the study of output terminal voltages, internal losses and performance. In Electrical Power Conference 2007 (pp. 387-392). Montreal: IEEE Canada.

18. Barote, L., Marinescu, C., \& Georgescu, M. (2009). VRB modeling for storage in stand-alone wind energy systems (pp. 1-6). Bucharest: PowerTech 2009 IEEE Bucharest.

19. Barote, L., Georgescu, M., \& Marinescu, C. (2009). Smart storage solution for wind systems (pp. 1-6). Bucharest: PowerTech 2009 IEEE Bucharest.

20. Barote, L., Weissbach, R., Teodorescu, R., Marinescu, C., \& Cirstea, M. (2008). Stand-alone wind system with vanadium redox battery energy storage. In Proc International Conference Optimization Electrical Electron Equipment (pp. 407-412).

21. Rathore, A. K., Patil, D. R., \& Srinivasan, D. (2016). Non-isolated bidirectional soft-switching current-fed $L C L$ resonant DC/DC converter to Interface energy storage in DC microgrid. IEEE Transactions on Industry Applications, 52(2), 1711-1722.

22. Amjadi, Z., \& Williamson, S. S. (2014). Digital control of a bidirectional DC/DC switched capacitor converter for hybrid electric vehicle energy storage system applications. IEEE Transactions on Smart Grid, 5(1), 158-166.

23. García, P., Arboleya, P., Mohamed, B., \& Vega, A. A. C. (2016). Implementation of a hybrid distributed/centralized real-time monitoring system for a DC/AC microgrid with energy storage capabilities. IEEE Transactions on Industrial Informatics., 12(5), 1900-1909.

24. Korunović, L. M., Sterpu, S., Djokić, S., Yamashita, K., Villanueva, S. M., \& Milanović, J. V. (2012). Processing of load parameters based on existing load models. In Proc 3rd IEEE International Conference Innovative Smart Grid Technologies (pp. 1-6)

25. Choi, B.-K., Chiang, H.-D., Li, Y. H., Chen, Y.-T., Huang, D.-H., \& Lauby, M. G. (2006). Measurement-based dynamic load models: Derivation, comparison, and validation. IEEE Transactions on Power Apparatus and Systems, 21(3), 1276-1283.

26. Rudolph, G. (1994). Convergence analysis of canonical genetic algorithms. IEEE Transactions on Neural Networks, 5(1), 96-101.

27. Knyazkin, V., Canizares, C. A., \& Soder, L. H. (May 2004). On the parameter estimation and modeling of aggregate power system loads. IEEE Transactions on Power Apparatus and Systems, 19(2), 1023-1031.

28. Zhu, Y., \& Tomsovic, K. (2002). Adaptive power flow method for distribution system with dispersed generation. IEEE Transactions on Power Delivery, 17(3), 822-827.

29. Fortes, M. Z., Ferreira, V. H., \& Coelho, A. P. F. (2013). The induction motor parameter estimation using genetic algorithm. Latin America Transactions IEEE, 11(5), 1273-1278.
30. Duan, F., Živanović, R., Al-Sarawi, S., \& Mba, D. (2016). Induction motor parameter estimation using sparse grid optimization algorithm. IEEE Transactions on Industrial Informatics, 12(4), 1453-1461.

31. Ju, P., Wu, F., Shao, Z.-Y., Zhang, X.-P., Fu, H.-J., Zhang, P.-F., He, N.-Q., \& Han, J.-D. (2007). Composite load models based on field measurements and their applications in dynamic analysis. IET Generation, Transmission \& Distribution, 1(5), 724-730.

32. Zhou, H. Q., Mao, C., Ju, P., et al. (2008). An identifiability analysis of a synthetic load model with the distribution network considered. Automation of Electric Power Systems, China, 32(16), 16-19.

\section{Submit your manuscript to a SpringerOpen ${ }^{\circ}$ journal and benefit from:}

- Convenient online submission

- Rigorous peer review

- Open access: articles freely available online

- High visibility within the field

- Retaining the copyright to your article

Submit your next manuscript at $\boldsymbol{\nabla}$ springeropen.com 